\title{
Characterization of Klebsiella pneumoniae Strains Isolated from Urinary Tract infections: Detection of ESBL Characteristics, Antibiotic Susceptibility and RAPD Genotyping
}

\author{
MUSTAFA ONUR ALADAG ${ }^{1 *}$, AHMET UYSAL ${ }^{1}$, NIYAZI DUNDAR², YUSUF DURAK ${ }^{3}$ \\ and ERDOGAN GUNES ${ }^{3}$ \\ ${ }^{1}$ Department of Medicinal Laboratory, Vocational School of Health Services, Selcuk University, Konya, Turkey \\ ${ }^{2}$ Faculty of Dentistry Research Center, Selcuk University, Konya, Turkey \\ ${ }^{3}$ Department of Biology, Science Faculty, Selcuk University, Konya, Turkey
}

Submitted 31 January 2013, revised 5 March 2013, accepted 17 September 2013

\begin{abstract}
In this study, a hundred Klebsiella pneumoniae strains isolated from urinary tract infections were evaluated in terms of genotyping, susceptibility to certain antibiotics and detection of extended spectrum of beta lactamase (ESBL) production. The random amplified polymorphic DNA (RAPD-PCR) method was used to identify the genetic differentiation of K. pneumoniae isolates. A total of 26 different DNA bands ranging between $334 \mathrm{bp}$ and $28033 \mathrm{bp}$ were detected among the strains. It was found that $100 \mathrm{~K}$. pneumoniae strains revealed 11 different RAPD profiles. Antibiotic susceptibility tests were conducted using a disc diffusion method against 16 antibiotics. Fifty-five different resistance profiles were determined among the strains. ESBL-productions of the strains were determined by the double disc synergy test (DDST) and ESBL E-test methods. ESBL production rates among the strains were found to be $55 \%$ by E-test method and $45 \%$ by DDST method. While ESBL-producing K. pneumoniae strains showed the greatest resistance to penicillin G (100\%), followed by piperacillin (92.7\%) and erythromycin (85.4\%), the resistance rates of non ESBLproducing strains to those antibiotics were determined as $97.8 \%, 88.8 \%$ and $88.8 \%$, respectively. Both groups of strains showed the highest sensitivity to meropenem. Based on the results obtained from the study, it was concluded that the detection of ESBL-producing strains by the E-test method was more sensitive than by the DDST method. Phenotypic and genotypic identification methods should be used together to detect ESBL presence. The RAPD-PCR method alone will not be adequate in the genotyping of the strains and alternative DNA-based methods should be used.
\end{abstract}

Ke y words: Klebsiella pneumoniae, antibiotic resistance, ESBL, E-test method, RAPD typing

\section{Introduction}

ESBL-producing bacteria are increasingly causing urinary tract infections (UTI) both in hospitalized and outpatients. The increase of drug resistance among these organisms has made the therapy of UTI difficult and has led to greater use of expensive broad spectrum antibiotics such as third generation cephalosporins. Detection of ESBLs using conventional antimicrobial susceptibility methods and a delay in the detection and reporting of ESBL production by gram-negative bacilli are associated with prolonged hospital stay and increased morbidity, mortality and health care costs. (Mehrgan and Rahbar, 2008). The detection of ESBL production is important. ESBL positive strains are associated with increased mortality when compared to ESBL negative strains (Kim and Pai, 2002).

Klebsiella species, particularly Klebsiella pneumoniae, are important opportunistic nosocomial patho- gens causing a variety of infections including urinary tract infections, pneumonia, septicemia, wound infections and infections in intensive care units. It has been estimated that Klebsiella spp cause $5-7 \%$ of the total bacterial nosocomial infections (Podschun and Ullmann, 1998). Since 1983, multi-resistant K. pneumoniae has been increasingly recognized internationally as a cause of hospital-acquired infections. Because of the acquisition of plasmids which code for the production of extended-spectrum $\beta$-lactamases (ESBL), ESBL-producing microorganisms are more resistant to extended-spectrum cephalosporins and aminoglycosides than non ESBL-producing microorganisms (Eisen et al., 1995).

Most of the ESBLs in E. coli and K. pneumoniae are derived from TEM or SHV type $\beta$-lactamases by one or more amino acid substitutions that confer resistance to extended-spectrum cephalosporins. Recently more non-TEM and non-SHV derived ESBLs such

\footnotetext{
* Corresponding author: M.O. Aladag, Department of Medicinal Laboratory, Vocational School of Health Services, Selcuk University, Konya, Turkey; phone: +90 332223 1068; fax: +90 332 2416210; e-mail: moaladag@selcuk.edu.tr; moaladag72@gmail.com
} 
as CTX-M related enzymes have been identified over an extremely wide geographical area (Li et al., 2003). These multi-resistant isolates produce the novel plasmid-mediated $\beta$-lactamases CTX-1, SHV-2 and SHV-3 which are able to hydrolyze oxyimino $\beta$-lactamases (Pitout et al., 2005).

Among all the genome fingerprinting PCR methods, random amplified polymorphic DNA (RAPD) is used for demonstrating differences between bacteria. RAPD can be used for the typing of organisms without previous knowledge of DNA sequences (Mohamudha et al., 2010, Dobara et al., 2010). The use of a single primer leads to the amplification of several DNA fragments randomly distributed throughout the genome. RAPD has received considerable attention in recent years as a molecular typing method due to its simplicity, sensitivity, flexibility and relatively low cost. The ability of RAPD to type a wide variety of bacteria strains in a short time suggests that it will be a useful molecular epidemiological tool (Dobara et al., 2010).

The aim of the present study was to investigate the presence and rates of ESBL and antibiotics susceptibilities and the genotypic identification of Klebsiella pneumoniae strains isolated from urinary tract infections in a hospital in Konya, Turkey.

\section{Experimental}

Material and Methods

Sample collection and isolation of strains. A hundred K. pneumoniae strains isolated from urine samples belonging to patients with urinary tract infections were collected during May 2010-July 2011. The collected samples were inoculated in sterile Petri dishes containing ready prepared EMB agar and blood agar media and incubated at $35^{\circ} \mathrm{C}$ for $18-24$ hours. The isolated colonies were subcultured and purified for characterization. The isolated bacteria were identified according to Bergey's Manual of Determinative Bacteriology (Brenner, 1986) and confirmations of the strains were carried out using the API-20E (BioMérieux) test system.

Identification of K. pneumoniae isolates by API $20 \mathrm{E}$ test. The $\triangle \mathrm{PI} 20 \mathrm{E}$ test was performed in accordance with the manufacturer's protocol (BioMérieux, Marcy l'Etoile, France). All cultures were transferred onto $5 \%$ sheep blood agar plates prior to the inoculation of the API 20E strips. A bacterial suspension approximating a $0.5 \mathrm{McF}$ arland standard was used for inoculation. All strips were incubated at $35^{\circ} \mathrm{C}$ for $24 \mathrm{~h}$. The addition of reagents and the interpretation of reactions were performed in accordance with the manufacturer's directions. The 20 biochemical test reactions on the strip were converted into an octal profile number.
Each profile number was then decoded using the Analytical Profile Index. Diagnosis of Klebsiella spp. was conducted by Apiweb ${ }^{\mathrm{TM}}$.

Antibiotic susceptibility test. The standard KirbyBauer disk diffusion method was used to determine the antibiotic sensitivity profiles of the K.pneumoniae isolates (CLSI, 2008) for 16 antimicrobial agents [meropenem $(10 \mu \mathrm{g})$, aztreonam $(30 \mu \mathrm{g})$, erythromycin $(10 \mu \mathrm{g})$, ciprofloxacin $(5 \mu \mathrm{g})$, piperacillin $(30 \mu \mathrm{g})$, penicillin $\mathrm{G}(10 \mathrm{U})$, norfloxacin $(10 \mu \mathrm{g})$, tetracycline $(30 \mu \mathrm{g})$, netilmicin $(30 \mu \mathrm{g})$, chloramphenicol $(30 \mu \mathrm{g})$, amoxicillin/clavulanic acid $(30 \mu \mathrm{g})$, cephalexin $(30 \mu \mathrm{g})$, cefoxitin $(30 \mu \mathrm{g})$, ceftazidime $(30 \mu \mathrm{g})$, ceftriaxon $(30 \mu \mathrm{g})$ and cefotaxime $(30 \mu \mathrm{g})]$. A $12 \mathrm{~cm}$ Mueller-Hinton Agar (MHA) medium plate was swabbed with BHI (Brain Heart Infusion) broth inoculated with K.pneumoniae and incubated to a turbidity of $0.5 \mathrm{McF}$ arland standards. Sixteen commercially prepared antimicrobial agent disks were placed on the inoculated plates. The plates were incubated at $35^{\circ} \mathrm{C}$ for 18 to $20 \mathrm{~h}$. The diameters (in millimeters) of the clear zones of growth inhibition around the antimicrobial agent disks, including the $6 \mathrm{~mm}$ disk diameter, were measured using a ruler. Zone diameters were interpreted using guidelines from the CLSI (2008). E. coli ATCC 25922 was used for quality control.

All samples were screened for the production of an ESBL by the double disc synergy test (DDST) as described by Jalier et al. (1998) and the E-test (Biomerieux). The strains were pre-incubated in brain heart infusion broth (BHIB) at $37^{\circ} \mathrm{C}$ and the optimal density of $0.5 \mathrm{McF}$ arland standards. This bacterial suspension was swabbed with sterile cotton on to a Mueller-Hinton agar medium. The antagonistic tests were conducted with antibiotic discs of amoxicillin/clavulanic acid $(20 / 10 \mu \mathrm{g})$ and cefotaxime $(30 \mu \mathrm{g})$, ceftazidime $(30 \mu \mathrm{g})$ and ceftriaxon $(30 \mu \mathrm{g})$ were placed at a distance of about $4 \mathrm{~cm}$ apart from each other and incubated. After incubation a clear extension of the edge of the inhibition zone of any of the antibiotics towards the disk containing clavulanic acid-CA $(10 \mu \mathrm{g})$ was interpreted as positive for ESBL production.

An E test ESBL strip (Biomerieux) is a plastic drugimpregnated strip, one end of which generates a stable concentration gradient of ceftazidime (MIC test range, $0.25-16 \mathrm{mg} / \mathrm{l}$ ) and the remaining end of which generates a gradient of ceftazidime (MIC test range, $0.016-1 \mathrm{mg} / \mathrm{l}$ ) plus $4 \mathrm{mg} / \mathrm{l}$ clavulanic acid. The E-test procedure, reading and interpretation were carried out according to the manufacturer's instructions. Isolated colonies from an overnight agar plate were suspended in saline $(0.85 \% \mathrm{NaCl})$ to achieve an inoculum equivalent to $0.5 \mathrm{McF}$ arland standards. This suspension was swabbed on a Mueller-Hinton agar plate (Oxoid, UK) and allowed to dry completely. An ESBL E-test strip 
was then applied to the agar surface with sterile forceps and the plate was incubated at $36^{\circ} \mathrm{C}$ for $18 \mathrm{~h}$. The ESBL results were read either as MIC values or observation of 'phantom' zones or deformation of inhibition ellipses. $A$ reduction of $\mathrm{MIC}$ by $\geq 3$ two-fold dilutions in the presence of clavulanic acid is indicative of ESBL production. In addition, multiple antibiotic resistance (MAR) indexing of K. pneumoniae strains was determined according to Krumperman (1983).

Extraction of genomic DNA. DNA genomes were extracted from the bacterial isolates using a DNA extraction kit (Dr Zeydanl, Life Sciences) as directed by the manufacturer and the supernatants were stored in a freezer at $-20^{\circ} \mathrm{C}$ for PCR analysis.

Random Amplified Polymorphic DNA (RAPD) Fingerprinting. RAPD was carried out according to Williams et al. (1990) with some modification. PCR reactions were prepared in a total volume of $50 \mu \mathrm{l}$ per tube, containing $5 \mu \mathrm{l}(50 \mathrm{ng} / \mu \mathrm{l})$ of chromosomal DNA, $0.7 \mu \mathrm{l}(5 \mathrm{U} / \mu \mathrm{l}) \mathrm{Taq}$ DNA polymerase (Fermentas, Thermo Scientific), $3 \mu \mathrm{MgCl}_{2}(25 \mathrm{mM}), 5 \mu \mathrm{ltaq}$ buffer, $30.3 \mu \mathrm{l}$ PCR buffer, $1 \mu \mathrm{l}(25 \mathrm{pmol})$ primer (OPA-02). The following primer (OPA-02 5'TGCCGAGCTG3') was used in this study.

The amplifications were done in a thermal cycler (Eppendorf) programmed for the first cycles to denature for $1 \mathrm{~min}$ at $95^{\circ} \mathrm{C}$. Then came a program of $40 \mathrm{cycles}$ of 1 min denaturation at $94^{\circ} \mathrm{C}, 1 \mathrm{~min}$ annealing at $36^{\circ} \mathrm{C}$ and a 2 min primer extension at $72^{\circ} \mathrm{C}$ followed by a final step of amplification of $7 \mathrm{~min}$ at $72^{\circ} \mathrm{C}$.
Gel preparation, sample loading and detection. Amplification products were resolved by electrophoresis on $1.2 \%$ agarose gel that was prepared in $1 \mathrm{X}$ TBE (Tris/Borate/EDTA) buffer and mixed with $0.5 \mu \mathrm{g} / \mathrm{ml}$ of ethidium bromide. The agarose gel was transferred to an electrophoresis cell with $1 \mathrm{X}$ TBE buffer. $20 \mu \mathrm{l}$ of each samples was mixed with $4 \mu$ loading dye and loaded into the gel and $5 \mu \mathrm{l}$ of DNA markers (Gene ruler $100 \mathrm{bp}$ plus, Lambda DNA/Hind III) (Fermentas, Thermo Scientific) and Sigma Direct Load (Sigma Aldrich) were loaded into the well of the gel. 80 volts for 2 hours as $7.5 \mathrm{v} / \mathrm{cm}$ of the gel was applied. DNA bands were visualized using a $366 \mathrm{~nm}$ UV transilluminator and photographed with the UVP GelDoc $\mathrm{It}^{\mathrm{T} \mathrm{M}}$ Imaging System.

\section{Results}

In this study it was found that 45 (45\%) K. pneumoniae strains produced ESBL in the double discs synergy test and 55 (55\%) strains produced ESBL in the E-test. Both methods demonstrated the presence of ESBL in 55 of the isolates. ESBL-producing K. pneumoniae strains displayed higher antibiotics resistance ratios than non ESBL-producing K. pneumoniae strains. Table I shows the antibiotic resistance and susceptibility ratios of ESBL-producing and non ESBL-producing K. pneumoniae.

The antibiotic susceptibility test by disc diffusion method found that ESBL-producing K.pneumoniae

Table I

Antibiotic susceptibility patterns of ESBL-producing and non ESBL-producing Klebsiella pneumoniae strains

\begin{tabular}{|l|c|c|c|c|c|c|}
\hline \multirow{2}{*}{ Antibiotics } & \multicolumn{2}{|c|}{ non ESBL-producing K.pneumoniae } & \multicolumn{2}{c|}{ ESBL-producing K.pneumoniae } \\
\cline { 2 - 7 } & $\begin{array}{c}\mathrm{R}^{*} \\
\mathrm{n}(\%)\end{array}$ & $\begin{array}{c}\mathrm{I}(\%) \\
\mathrm{n}\end{array}$ & $\begin{array}{c}\mathrm{S}(\%) \\
\mathrm{n}(\%)\end{array}$ & $\begin{array}{c}\mathrm{R} \\
\mathrm{n}(\%)\end{array}$ & $\mathrm{n}(\%)$ \\
\hline Meropenem (MEM) & $1(2.2 \%)$ & $1(2.2 \%)$ & $43(95.6 \%)$ & $5(9 \%)$ & $1(1.8 \%)$ & $49(89.2 \%)$ \\
\hline Aztreonam (ATM) & $7(15.5 \%)$ & $3(6.6 \%)$ & $35(77.9 \%)$ & $27(49 \%)$ & $1(1.8 \%)$ & $27(49.2 \%)$ \\
\hline Erythromycine (E) & $40(88.8 \%)$ & $4(8 \%)$ & $1(2.2 \%)$ & $47(85.4 \%)$ & $5(9 \%)$ & $3(5.6 \%)$ \\
\hline Ciprofloxacin (CIP) & $3(6.6 \%)$ & $4(8.6 \%)$ & $1(2.2 \%)$ & $10(18.1 \%)$ & $6(10.9 \%)$ & $39(71 \%)$ \\
\hline Penicillin G(P) & $44(97.8 \%)$ & - & $1(2.2 \%)$ & $55(100 \%)$ & - & - \\
\hline Piperacilline (PRL) & $40(88.8 \%)$ & $3(6.6 \%)$ & $2(4.6 \%)$ & $51(92.7 \%)$ & $3(5.4 \%)$ & $2(1.9 \%)$ \\
\hline Norfloxacin (NOR) & $3(6.6 \%)$ & $(8.8 \%)$ & $38(84.6 \%)$ & $12(21.8 \%)$ & $2(3.6 \%)$ & $41(74.6 \%)$ \\
\hline Tetracyline (TE) & $12(26.6 \%)$ & $2(4.6 \%)$ & $31(68.8 \%)$ & $17(30.9 \%)$ & $2(3.6 \%)$ & $36(65.5 \%)$ \\
\hline Netilmicin (NET) & $4(8.6 \%)$ & - & $41(91.4 \%)$ & $16(29 \%)$ & $4(7.2 \%)$ & $35(63.8 \%)$ \\
\hline Chloramphenicol (C) & $5(11.1 \%)$ & $4(8.8 \%)$ & $36(80.1 \%)$ & $11(20 \%)$ & $1(1.8 \%)$ & $43(78.2 \%)$ \\
\hline Amoxicillin/Clavulanic acid (AMC) & $12(26.6 \%)$ & $5(11.1 \%)$ & $28(62.3 \%)$ & $18(32.7 \%)$ & $12(21.8 \%)$ & $25(45.5 \%)$ \\
\hline Ceftazidime (CAZ) & $6(13.3 \%)$ & $5(11.1 \%)$ & $34(75.6 \%)$ & $25(45.4 \%)$ & $7(12.7 \%)$ & $23(41.9 \%)$ \\
\hline Ceftriaxon (CRO) & $5(11.1 \%)$ & $14(31.1 \%)$ & $26(57.8 \%)$ & $28(50.9 \%)$ & $8(14.5 \%)$ & $19(34.6 \%)$ \\
\hline Cefotaxime (CTX) & $5(11.1 \%)$ & $4(8.8 \%)$ & $36(80.1 \%)$ & $26(47.2 \%)$ & $5(9 \%)$ & $20(43.8 \%)$ \\
\hline Cefolaxine (CL) & $9(20 \%)$ & $11(24.4 \%)$ & $25(55.6 \%)$ & $29(52.7 \%)$ & $2(3.8 \%)$ & $24(43.5 \%)$ \\
\hline Cefoxitine (FOX) & $8(17.7 \%)$ & $6(13.3 \%)$ & $31(69 \%)$ & $7(12.7 \%)$ & $4(7.2 \%)$ & $44(80.1 \%)$ \\
\hline
\end{tabular}

* R: Resistant; I: Intermediate; S: Susceptible 


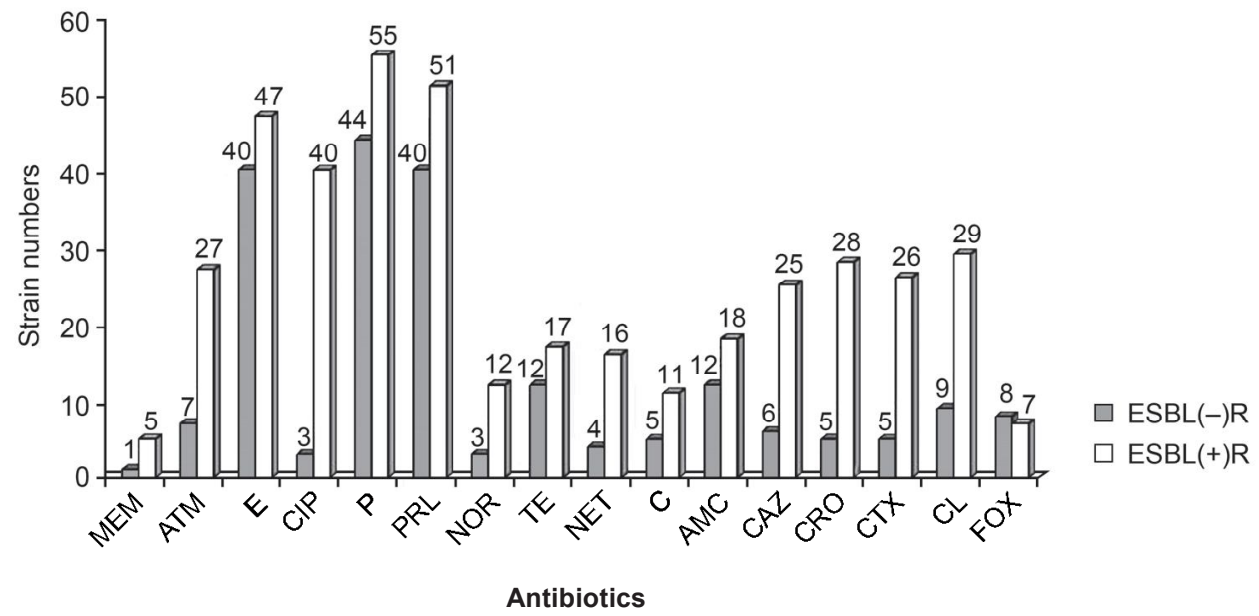

Fig. 1. Resistant strain numbers of $K$. pneumoniae isolates ESBL producing and ESBL non-producing

strains showed the highest antibiotic resistance to penicillin in 55 strains (100\%); piperacilline in 51 strains (92.7\%); erythromycin in 47 strains $(85.4 \%)$ and ceftriaxone in 28 (50.9\%) strains respectively (Fig. 1). The strains showed the lowest antibiotic resistance to meropenem in 5 strains (9\%); cefoxitin in 7 strains (12.7\%); ciprofloxacin in 10 strains (18.1\%) and norfloxacin in 12 strains (21.8\%). ESBL-producing K. pneumoniae strains showed the highest antibiotic resistance to penicillin in 44 strains (97.8\%); erythromycin and piperacillin in 40 strains (88.8\%) and tetracycline and amoxicillin/clavulanic acid in 12 strains $(26.6 \%)$ respectively. They showed the lowest antibiotic resistance to penicillin in one strain $(2.2 \%)$; norfloxacin and ciprofloxacin in 3 strains (6.6\%) and netilmicin in 4 strains
(8.6\%). It was found that non ESBL-producing strains showed high resistance to penicillin, erythromycin and piperacillin. ESBL-producing and non ESBL-producing K. pneumoniae strains showed the highest sensitivity to meropenem. While non ESBL-producing strains had high resistance to netilmicin and norfloxacin, ESBLproducing strains showed high sensitivity to cefoxitin and chloramphenicol.

Resistance profiles were formed based on the antibiotics that the strains were resistant to (Table II). According to this table, a total of 55 different resistance profiles were observed among $100 \mathrm{~K}$. pneumoniae strains. The majority of strains (98\%) were found to be resistant to two or more antibiotics. The most common resistance profile was identified in 23 strains and these

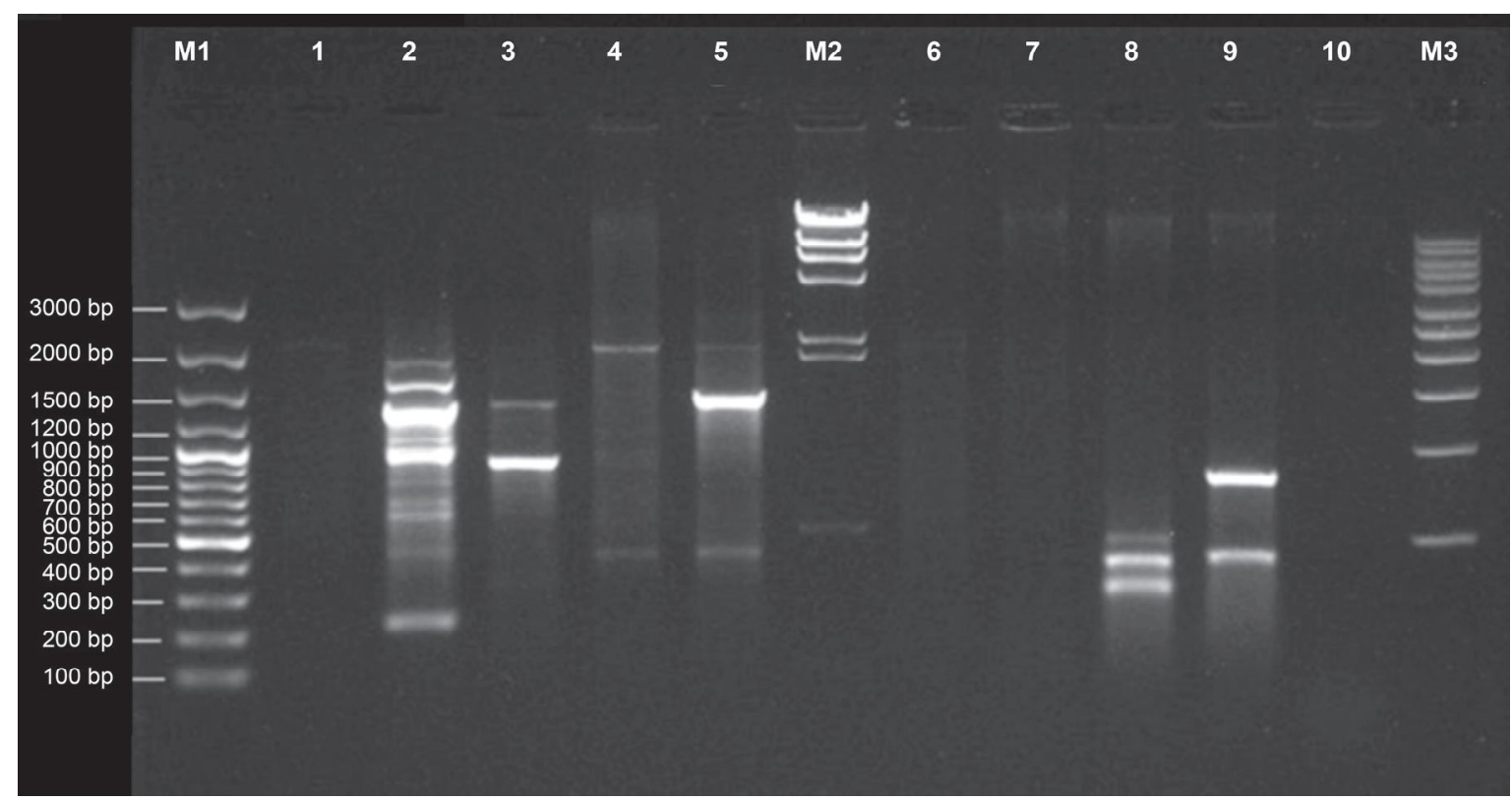

Fig. 2. Image of DNA bands extracted from K. pneumoniae strains and detected by RAPD-PCR method on agarose gel. M1: Marker (Gene ruler 100 bp plus), Lane 1: 2 numbered strain, Lane 2: 3 numbered strain, Lane 3: 4 numbered strain, Lane 4: 11 numbered strain, Lane 5: 13 numbered strain, M2: Marker (Lambda DNA/Hind III), Lane 6: 15 numbered strain, Lane 8: 26 numbered strain, Lane 9: 27 numbered strain, M3: Marker (Sigma Direct Load) 
Table II

Antibiotic resistance patterns of Klebsiella pneumoniae isolates.

\begin{tabular}{|c|c|c|c|c|}
\hline Resistance profiles & $\begin{array}{c}\text { Number } \\
\text { of isolates }\end{array}$ & $\%$ & Strains & $\begin{array}{l}\text { MAR } \\
\text { index }\end{array}$ \\
\hline $\mathrm{E}$ & 1 & 1 & 51 & 0.0625 \\
\hline $\mathrm{P}$ & 1 & 1 & 87 & 0.0625 \\
\hline P, PRL & 3 & 3 & $8,13,35$ & 0.125 \\
\hline E, PRL & 4 & 4 & $14,36,48,99$ & 0.125 \\
\hline E, P & 1 & 1 & 55 & 0.125 \\
\hline E, P, PRL & 23 & 23 & $\begin{array}{c}7,9,12,21,30,31,38,37 \\
42,47,53,54,56,58,64,67 \\
75,78,80,82,89,96,100\end{array}$ & 0.187 \\
\hline P, PRL, CAZ & 1 & 1 & 20 & 0.187 \\
\hline E, P, TE & 1 & 1 & 85 & 0.187 \\
\hline ATM, CAZ, CRO, FOX & 1 & 1 & 5 & 0.25 \\
\hline ATM, E, P, PRL & 3 & 3 & $59,84,97$ & 0.25 \\
\hline E, CIP, P, PRL & 1 & 1 & 40 & 0.25 \\
\hline E, P, PRL, TE & 3 & 3 & $1,23,63$ & 0.25 \\
\hline E, P, PRL, C & 3 & 3 & $15,16,86$ & 0.25 \\
\hline E, P, PRL, AMC & 3 & 3 & $18,19,95$ & 0.25 \\
\hline E, P, PRL, CL & 1 & 1 & 26 & 0.25 \\
\hline E, P, AMC, CL & 1 & 1 & 32 & 0.25 \\
\hline CIP, P, PRL, NOR & 1 & 1 & 41 & 0.25 \\
\hline P, PRL, TE, FOX & 2 & 2 & 71,72 & 0.25 \\
\hline ATM, E, CIP, P, PRL & 1 & 1 & 43 & 0.313 \\
\hline E, P, PRL, TE, C & 1 & 1 & 50 & 0.313 \\
\hline E, P, PRL, TE, AMC & 3 & 3 & $22,49,74$ & 0.313 \\
\hline E, P, PRL, TE, CL & 1 & 1 & 39 & 0.313 \\
\hline E, P, AMC, CL, FOX & 1 & 1 & 46 & 0.313 \\
\hline ATM, E, PRL, NET, CAZ, CRO & 1 & 1 & 52 & 0.375 \\
\hline E, P, PRL, TE, C, AMC & 2 & 2 & 10,29 & 0.375 \\
\hline P, PRL, TE, AMC, CAZ, CL & 1 & 1 & 17 & 0.375 \\
\hline ATM, E, P, PRL, CAZ, CRO, CL & 1 & 1 & 11 & 0.438 \\
\hline ATM, E, P, PRL, CAZ, CL, FOX & 1 & 1 & 93 & 0.438 \\
\hline ATM, E, P, PRL, CRO, CTX, CL & 1 & 1 & 73 & 0.438 \\
\hline ATM, P, PRL, CAZ, CRO, CTX, CL & 1 & 1 & 45 & 0.438 \\
\hline E, P, PRL, C, CRO, CTX, CL & 1 & 1 & 88 & 0.438 \\
\hline E, P, PRL, TE, NET, C AMC & 1 & 1 & 90 & 0.438 \\
\hline ATM, E, P,PRL, NOR, CRO, CTX, CL & 1 & 1 & 62 & 0.50 \\
\hline ATM, E, P,PRL, CAZ, CRO, CTX, CL & 1 & 1 & 81 & 0.50 \\
\hline ATM, E, PRL, AMC, CAZ, CRO, CTX, CL & 1 & 1 & 68 & 0.50 \\
\hline ATM, P, PRL, NET, CAZ, CRO, CTX, CL & 1 & 1 & 44 & 0.50 \\
\hline ATM, TE, NET, CAZ, CRO, CTX, CL, FOX & 1 & 1 & 6 & 0.50 \\
\hline E, CIP, P, PRL, NOR, TE, C, AMC & 1 & 1 & 92 & 0.50 \\
\hline E, P, PRL, AMC, CRO, CTX, CL, FOX & 1 & 1 & 5 & 0.50 \\
\hline ATM, E, P, PRL, NET, CAZ, CRO, CTX, CL & 2 & 2 & 3,70 & 0.563 \\
\hline ATM, E, P, PRL, AMC, CAZ, CRO, CTX, CL & 1 & 1 & 37 & 0.563 \\
\hline E, P, PRL, TE, NET, C, CRO, CTX, CL & 1 & 1 & 34 & 0.563 \\
\hline E, P, PRL, AMC, CAZ, CRO, CTX, CL, FOX & 1 & 1 & 65 & 0.563 \\
\hline ATM, E, CIP, P, PRL, NOR, CAZ, CRO, CTX, CL & 2 & 2 & 4,83 & 0.625 \\
\hline ATM, E, P, PRL, TE, C, CAZ, CRO, CTX, CL & 2 & 2 & 60,61 & 0.625 \\
\hline
\end{tabular}


Table II continued.

\begin{tabular}{|l|c|c|c|c|}
\hline \multicolumn{1}{|c|}{ Resistance profiles } & $\begin{array}{c}\text { Number } \\
\text { of isolates }\end{array}$ & $\%$ & Strains & $\begin{array}{c}\text { MAR } \\
\text { index }\end{array}$ \\
\hline ATM, E, P, PRL, TE, NET, AMC, CAZ, CRO, CTX, CL & 1 & 1 & 91 & 0.686 \\
\hline ATM, E, P, PRL, TE, NET, CAZ, CRO, CTX, CL, FOX & 1 & 1 & 24 & 0.686 \\
\hline MEM, ATM, E, P, PRL, TE, NET, CAZ, CRO, CTX, CL, FOX & 1 & 1 & 25 & 0.75 \\
\hline ATM, E, CIP, P, PRL, NOR, C, AMC, CAZ, CRO, CTX, CL & 1 & 1 & 69 & 0.75 \\
\hline ATM, E, P, PRL, NOR, TE, NET, AMC, CAZ, CRO, CTX, CL & 1 & 1 & 57 & 0.75 \\
\hline ATM, E, P, PRL, TE, NET, AMC, CAZ, CRO, CTX, CL, FOX & 1 & 1 & 28 & 0.75 \\
\hline ATM, E, P, PRL, TE, C, AMC, CAZ, CRO, CTX, CL, FOX & 1 & 1 & & 0.75 \\
\hline MEM, ATM, E, CIP, P, PRL, NOR, NET, AMC, CAZ, CRO, CTX, CL & 1 & 1 & & 27 \\
\hline ATM, E, CIP, P, PRL, NOR, TE, NET, AMC, CAZ, CRO, CTX, CL & 1 & 1 & 98 & 0.813 \\
\hline $\begin{array}{l}\text { MEM, ATM, E, CIP, P, PRL, NOR, TE, NET, C, AMC, CAZ, CRO, } \\
\text { TX, CL, FOX }\end{array}$ & 4 & 4 & $66,76,79,94$ & 1 \\
\hline
\end{tabular}

Table III

DNA band sizes and RAPD profiles of Klebsiella pneumoniae strains

\begin{tabular}{|l|l|c|}
\hline \multicolumn{1}{|c|}{ DNA band sizes $(\mathrm{bp})$} & \multicolumn{1}{|c|}{ K. pneumoniae strains } & Profile no \\
\hline 2492 & 2 & P1 \\
\hline $2056,1806,1491,1108,918,787,722,565,334$ & 3 & P2 \\
\hline 1658,1080 & 4 & P3 \\
\hline 2648,600 & 11 & P4 \\
\hline $2583,1700,590$ & 13 & P5 \\
\hline 2480 & 15 & P6 \\
\hline 502,422 & 26 & P7 \\
\hline 899,522 & 27 & P8 \\
\hline 28033 & $28,29,30,31,32,33,35,36,37,38,39,40,41,43,44,45,46$, & \\
& $47,48,49,50,51,52,53,54,79,80,81,83,85,86,89,95,96$ & P9 \\
\hline $1618,1608,1604$ & 92 & P10 \\
\hline 1618 & 97 & P11 \\
\hline
\end{tabular}

strains showed resistance to erythromycin, penicillin and piperacillin. This profile had a $23 \%$ rate among the strains. We determined 4 strains that developed resistance to all 16 antibiotics and only showed resistance to erythromycin and piperacillin. The majority of observed resistance profiles are observed to consist of one strain. Among all, 66, 76, 79 and 94 numbered strains showed the highest MAR index values. In 65 strains $(65 \%)$ showing resistance to at least four antibiotics, the MAR index was greater than 0.2. According to Krumperman (1983), it is claimed that strains which have an index higher than 0.2 come from a location in which antibiotics are intensively used.

In the present study genotypic analyses were performed on Klebsiella pneumoniae strains using the RAPD-PCR method (Fig. 2).

In 44 of 100 strains, we determined 11 different DNA profiles, with minimum1, maximum 9 DNA bands. A total of 26 different DNA bands ranging between 334 bp and 28033 bp were determined (Fig. 2).
Among the strains in which a DNA band was identified, 9 DNA bands were found in 1; 3 DNA bands were found in 2; 2 DNA bands were found in 4 and 1 DNA band was found in 37 strains (Table III).

A total of 9 DNA bands were found in K. pneumoniae strain no 3. It was found that the size of this band varied between 334-2056 bp. 3 DNA bands were observed in each 13 (590-2583 bp) and 92 numbered strain (1604-1618bp). Furthermore, 2 DNA bands with a size of 422-2648 bp were found in strains no 4, 11, 26 and 27 . The most common profile among the strains was profile no 9 with a size of $28033 \mathrm{bp}$. The prevalence of this profile among strains was found to be $84.09 \%$ (Table III).

\section{Discussion}

The identification of ESBL presence in microorganisms causing hospital and community-acquired infections is of great importance as antibiotic treatment 
will be determined accordingly, treatment costs will be reduced, and mortality and morbidity will decrease. Firstly the ESBL enzyme produced by the bacteria should be accurately identified (Isik et al., 2007). The CLSI has recommended scanning and phenotypic validation test based on the indication of beta-lactam/betalactamase inhibitor synergy for in vitro identification of ESBL-producing K. pneumoniae isolates. However, since DDST is still the most common, cheapest and easiest method for ESBL identification, it is used in various microbiology laboratories in Turkey and around the world. In the present study, $100 \mathrm{~K}$. pneumoniae strains were analyzed in terms of ESBL using DDST and ESBL E-tests. Although the analysis which used the DDST found ESBL-producing strains at the 45\% level, the E-test found ESBL-producing strains at the 55\% level. In this case, the E-test method can be considered as more reliable than DDST in the identification of ESBLproducing strains. In a similar study, Abacioglu et al. (1995) identified the ESBL-producing K. pneumoniae strain rate at 50\% using the DDST method and as $62.5 \%$ using the E-test method. Using the E-test method, Yucesoy et al. (1996) identified 57.1\% ESBL in K. pneumoniae isolates, which are hospital infection pathogens. Isık et al. (2007), found a 63.7\% ESBL production rate in K. pneumoniae strains using the DDST method and a $59.8 \%$ ESBL production rate using the E-test. The findings of our study are consistent with the findings of previous studies. Using the DDST method, Steward et al. (2001) identified ESBL production level as 84\% in K. pneumoniae strains. Vecauteren et al. (1997) identified ESBL-producing strains at an $81 \%$ level using the E-test method and at $97 \%$ using the DDST method. Cormican et al. (1996) carried out a study on 82 clinical isolates and reported that the E-test was $100 \%$ sensitive. In the same study, the double disc synergy test had a sensitivity of $87 \%$. As indicated in previous studies, the E-test method was found to be more sensitive than DDST in terms of identifying ESBL presence. Similarly, Drieux et al. (2008) carried out a study on Klebsiella and E. coli strains and reported that the E-test method had 98.6\% sensitivity, while the DDST method had 94.4\% sensitivity. Similarly, in our study the E-test method was found to be more sensitive than DDST. ESBL ratios and antibiotic resistance status were compared to previous studies with reference to data obtained by us. G. Bindayna et al. (2009) identified ESBL presence at $24.3 \%$ in K. pneumoniae strains and reported that carbapenems were the most effective antibiotics. Jalalpour (2011) identified 36\% ESBL presence in K. pneumoniae strains. Lin et al. (2012) identified ESBL presence at $14.9 \%$ in K. pneumoniae strains obtained from neonatal intensive care units and reported that imipenem was the most effective antibiotic against these strains. The ESBL ratio determined in our study is higher than the ratios of previous studies. However, our findings are consistent with previous studies in that the strains were most sensitive to carbanepems. In another study, Goyal et al. (2009), found 66.7\% ESBL-producing K. pneumoniae strains and reported that all of the strains were sensitive to meropenem with the highest resistance to ciprofloxacin (93.7\%). According to our findings, resistance to ciprofloxacin (18.1\%) was much lower than the findings of previous researchers. Despite this, findings on meropenem sensitivity were consistent with our findings. Sensitivity to ciprofloxacin in our findings was found to be lower than the findings of Krawczyk et al. (2005) and higher than those of other researchers. Behrooozi et al. (2010) reported the incidence of ESBL-producing K.pneumoniae strains as $12 \%$ and that the strains were most sensitive to ofloxacin (28\%), and most resistant (100\%) ampicillin, ceftazidime and cefalotin (100\%). Based on our findings, the identified resistance to ciprofloxacin (18.1\%) and norfloxacin $(21.8 \%)$ among quinolone group antibiotics were consistent with the findings of Behrooozi et al. (2010); however ESBL-producing strains were the most sensitive to $(9 \%)$ meropenem. Ceftazidime resistance was found to be $45.4 \%$. Ejaz et al. (2011) identified 71.7\% ESBL prevalence in K. pneumoniae strains isolated from urinary tract infections. They determined the highest resistance to ceftazidime (100\%), cefotaxime $(98.7 \%)$ and cefuroxime $(98.1 \%)$ and the lowest resistance to meropenem $(3.6 \%)$. In our study, resistance levels to ceftazidime (45.4\%), cefotaxime (47.2\%) and the prevalence of ESBL-producing strains were found to be lower than the findings of Ejaz et al. (2011).

55 different resistance types were determined among $K$. pneumoniae strains. Comparison of the resistance profile with the profiles obtained from RAPD study showed that there was great phenotypic variety between the strains. However, the strains which were different in phenotype were divided into 11 different genotypes identified by RAPD. Analysis of the distribution of profiles with the same band size according to strains showed that these strains displayed multiple antibiotic resistances. In other words, the strains showing the same genotype were found to be phenotypically different. It was observed that 34 strains that had a DNA band with a size of $28033 \mathrm{bp}$ were dominant among the 44 strains showing the band profile (Table III). The different phenotypes of these strains indicate that they come from regions where antibiotics are intensely used and thus they phenotypically differed by acquiring resistance to these antibiotics (Krumperman, 1983). Eisen et al. (1995) found that a single epidemic strain type in K. pneumoniae strains determined by RAPDDNA, plasmid profile and phenotypic analyses was prevalent among the patients. Lopes et al. (2005) identified 26 RAPD genotypes among $30 \mathrm{~K}$. pneumoniae 
strains. In addition, the researchers identified 3 different antibiotic resistance profiles among these strains. The typing percentage of the researchers was higher than in our findings. Despite this, 55 different resistance profiles identified in our study are much higher than the data reported by Lopes et al. (2005). 34 (77.2\%) of 44 strains typed by RAPD had one DNA band. In this case, it can be thought that K. pneumoniae strains with a 28033 bp DNA band can come from a dominant epidemic origin. Dobara et al. (2010) identified 5 different R $\Lambda P D$ genotypes and 3 different antibiotic resistant profiles among K. pneumoniae strains. The genotype and phenotype percentages identified by the researchers were found to be lower than in our findings. Peng et al. (2002) found that 20 ESBL-producing K. pneumoniae strains formed 11 different types by RAPD method. In a similar study, Sharma et al. (2007) identified 23 different DNA profiles in 40 ESBL-producing K. pneumoniae strains using the RAPD method and found that DNA patterns at $300 \mathrm{bp}$ size were common. The typing percentages determined by these researchers are consistent with our findings.

In conclusion, antimicrobial resistance is a rapidly changing challenge and an increase in antibiotic resistance levels of the bacteria has been a global problem. One of the most important reasons for this is indiscriminate use of antibiotics. As antibiotic use increases, bacteria develop resistance mechanisms and it becomes difficult to treat their infections. This increases treatment costs and extends treatment time. A detailed and accurate identification of the bacteria that cause infections helps clinicians. Phenotypic and genotypic identification methods should be used; comparative studies using more than one method should be conducted and more than one method should be used to identify ESBL presence. There are some advantages of the RAPD technique such as that it requires no DNA probes or sequence information for the specific primers, and that it involves no blotting or hybridization steps, hence, it is quick, simple and efficient, and it requires only small amounts of DNA. Despite all these advantages, there are some disadvantages of this method. Nearly all RAPD markers are dominant, i.e. it is not possible to distinguish whether a DNA segment is amplified from a locus that is heterozygous ( 1 copy) or homozygous ( 2 copies). Co-dominant RAPD markers, observed as differentsized DNA segments amplified from the same locus, are detected only rarely. PCR is an enzymatic reaction, therefore, the quality and concentration of template DNA, concentrations of PCR components, and the PCR cycling conditions may greatly influence the outcome. Thus, the RAPD technique is notoriously laboratorydependent and needs carefully developed laboratory protocols to be reproducible. Mismatches between the primer and the template may result in the total absence of PCR product as well as in a merely decreased amount of the product. Thus, the RAPD results can be difficult to interpret. Another disadvantage is the lack of prior knowledge about the identity of the amplification products. Because of these reasons, the RAPD-PCR method alone will not be adequate for the genotyping of the strains. Our results should be developed by more sensitive DNA studies such as pulsed-field gel electrophoresis (PFGE), restriction fragment length polymorphism (RFLP) and nucleotide sequence analysis.

ESBL production of $K$. pneumoniae strains that cause urinary system infections should be followed via genotypic and phenotypic methods; their types should be identified and periodical identification and surveillance studies should be carried out on antibiotic resistance levels.

\section{Acknowledgement}

We would like to thank Selcuk University Scientific Research Projects Coordinating Office (BAP) for supporting this project financially (Project No: 10401050).

\section{Literature}

Abacioglu Y.H., M. Yucesoy, Z. Gulay and N. Yulug. 1995. Comparison of E-test and double disc synergy methods in detection of extended spectrum beta-lactamases (in Turkish). Infeksiyon. Derg. 9: 93-95.

Behrooozi A., M. Rahbar and J.V. Yousefi. 2010. Frequency of extended spectrum beta-lactamase (ESBLs) producing Escherichia coli and Klebseilla pneumoniae isolated from urine in an Iranian 1000-bed tertiary care hospital. African. J. Microbiol. Res. 4: 881-884. Bindayna, K.M., C.S. Abiola and A.E. Jamsheer. 2009. Prevalence of extended-spectrum beta-lactamase-producing Enterobacteriaceae in Bahrain. J. Infect. and Pub. Health. 2: 129-135.

Brenner D.J. 1985. Family I. Enterobacteriaceae. In: Bergey's Manual of Systematic Bacteriology (Holt, J.G., Krieg, N.R., Sneath, P.H.A., Staley, J.T. and Williams, S.T. (eds). Williams nad Wilkins. Baltimore. Cormican M.G., A. Marshall and R.N. Jones. 1996. Detection of extended-spectrum beta-lactamase producing strains by the E-test ESBL screen. J. Clin. Microbiol. 34: 1880-1884.

Dobara M.I.A, M.A. Deya, E.M. Elsawy and H.H. Mohamed. 2010. Antibiotics susceptibility and genotype patterns of Escherichia coli, Klebsiella pneumoniae and Pseudomonas aeruginosa isolated from urinary tract infected patients. Polish J. Microbiol. 20:207-212. dos Santos D.F., F.C. Pimenta, R. Alves, E.R. Montalvao, D.B. dos Santos and J.R. do Carmo Filho. 2008. Extended-spectrum $\beta$-lactamases producing Klebsiella pneumoniae isolated in two hospitals in Goiania/Brazil: detection, prevalence, antimicrobial susceptibility and molecular typing. Brazilian J. Microbiol. 39: 608-612.

Clinical and Laboratory Standards Institute (CLSI) 2008. Performance standarts for antimicrobial susceptibility testing, Eighteenth informational supplement, CLSI document M100-S18, pp. 34-38, Wayne, Penn., USA.

Drieux L., F. Brossier, W. Sougakoff and V. Jarlier. 2008. Phenotypic detectin of extended-spectrum beta-lactamase production in Enterobacteriaceae review and bench guide. Clin. Microbiol. Infect. 14: 19-103. 
Eisen D., E.G. Russell, M. Tymms, E.J. Roper, M.L. Grayson and J. Turnidge. 1995. Random amplified polymorphic DNA and plasmid analyses used in investigation of an outbreak of multiresistant Klebsiella pneumoniae. J. Clin. Microbiol. 33:713-717.

Ejaz H., I. Haq, A. Zafar, S. Mahmood and M.M. Javed. 2011. Urinary tract infections caused by extended spectrum $\beta$-lactamase (ESBL) producing Escherichia coli and Klebsiella pneumoniae. African J. Biotechnol. 10: 16661-16666.

Goyal A, K.N. Prasad, A. Prasad, S. Gupta, U. Ghoshal and A. Ayyagari. 2009. Extended spectrum $\beta$-lactamases in Escherichia coli \& Klebsiella pneumoniae \& associated risk factors. Indian. J. Med. Res. 129: 695-700.

Isık F., U. Aslan and I. Tuncer. 2007. Comparison of three methods in detection of extended spectrum beta-lactamases in Kleb siella pneumoniae strains isolated from blood cultures (in Turkish). Ankem Derg. 21:165-170.

Jalalpour S. 2011. Survey frequency of extended-spectrum beta lactamases (ESBLs) in Escherichia coli and Klebsiella pneumoniae strains isolated from urinary tract infection in Iran. African J. Microbiol. Res. 5: 3711-3715.

Jalier V., M.H. Nicolas, G. Fournier and A. Philippon. 1998. Extended broad-spectrum $\beta$-lactamases conferring transferable resistance and susceptibility patterns. Rev. Infect. Dis. 10: 867-878. Kim Y.K. and H. Pai. 2002. Bloodstream Infections by ExtendedSpectrum \{beta\}-Lactamase-Producing Escherichia coli and Klebsiella pneumoniae in Children: Epidemiology and Clinical Outcome. Antimicrob. Agents Chemother. 46: 1481-1491.

Krawczyk B., A. Samet, E. Czarniak, J. Szczapa and J. Kur. 2005. Extended-spectrum $\beta$-lactamase-producing Klebsiella pneumoniae in a neonatal unit: control of an outbreak using a new ADSRRS technique. Polish J. Microbiol. 54: 105-110.

Krumperman P.H. 1983. Multiple antibiotic resistance indexing of Escherichia coli to identify high-risk sources of fecal contamination of foods. Appl. and Environ. Microbiol.46:165-170.

Li C.R.,Y. Li and P.A. Zhang. 2003. Dissemination and spread of CTX-M extended-spectrum- $\beta$-lactamases among clinical isolates of Klebsiella pneumoniae in central China. Antimicrobial Agents. 22: 521-525.

Lin R., B. Wu, X.F. Xu, X.C. Liu, H. Ye and G.Y. Ye. 2012. Extended-spectrum beta-lactamase-producing Klebsiella pneumoniae infection in a neonatal intensive care unit. World J Pediatr. 8: 268-271
Lopes A.C.S, J.F. Rodrigues and M.A.M. Junior. 2005. Molecular typing of Klebsiella pneumoniae isolates from public hospitals in Refice, Brazil. Microbiological Res. 160: 37-46.

Mehrgan H. and M. Rahbar. 2008. Prevalence of extended-spectrum betalactamase-producing Escherichia coli in a tertiary care hospital in Tehran, Iran. Int. J. Antimicrob. Agents 31: 1471-1451.

Mohamudha P.R., A, N Srinivas, D. Rahul, B.N. Harish and S.C. Parija. 2010. Molecular epidemiology of multidrug resistant extended-spectrum $\beta$-lactamase producing Klebsiella pneumoniae outbreak in a neonatal intensive care unit. Int. J. Collaborative Res. Int. Med. Pub. Health. 2:226-237.

Peng S.H., L.I. Cong-Rong, C.I.A. Xuan, S.H.I. Jin-Ling, L.I. Hong-Xia and L.I. Yan. 2002. Genotyping of ESBL producing Klebsiella pneumoniae by RAPD. China J Nosocomiol. 12: 494-496. Pitout J.D.D., P. Nordmann, K. B. Laupland and L. Poirel. 2005. Emergence of Enterobacteriaceae producing extended-spectrum $\beta$-lactamases (ESBLs) in the community. J. Antimicrob. Chemotherapy 56: 52-59.

Podschun R. and U. Ullmann. 1998. Klebsiella spp. as nosocomial pathogens: epidemiology, taxonomy, typing methods, and pathogenicity factors. Clin. Microbiol. Rev. 11: 589-603.

Sharma A., S.K. Singh and S. Patra. 2007. Intra and Interspecies Variations among Environmental Klebsiella Isolates. Asian J. Exp. Sci. 21: 435-443.

Steward C.D., J.K. Rasheed, S.K. Hubert, J.W. Biddle, P.M. Raney, G.J. Anderson, P.P. Williams, K.L. Brittain, A. Oliver, J.E.Jr McGowan and F.C. Tenover. 2001. Characterization of clinical isolates of Klebsiella pneumoniae from 19 laboratories using the National Committee for Clinical Laboratory Standards extendedspectrum beta-lactamase detection methods. J. Clin. Microbiol. 39: 2864-2872.

Tuon F.F., K. Margot, T. Marcos, S.R. Penteado-Filho and L. Gortz. 2010. Klebsiella ESBL bacteremia-mortality and risk factors. Brazilian J. Infect. Dis. 15: 594-598.

Vercauteren E., P. Descheemaeker, M. Leven, C.C. Sanders and H. Goossens. 1997. Comparison of screening methods for detection of extended-spectrum beta-lactamases and their prevalence among blood isolates of Escherichia coli and Klebsiella spp. in a Belgian teaching hospital. Hospital J Clin. Microbiol. 35: 2191-2197.

Yucesoy M., K. Biberoglu and N. Yulug. 1996. Investigation of antibiotic susceptibility patterns of Gram negative bacteria causing infection by E-test (in Turkish). Infeksiyon Derg. 10: 229-233. 